\title{
Repeated muscle damage blunts the increase in heat strain during subsequent exercise heat stress
}

Riddle, T.G.; Dolci, A.; Fortes, M.B.; Walker, F.S.; Haq, A.; Riddle, T.; Walsh, N.P.

\section{European Journal of Applied Physiology}

DOI:

$10.1007 / \mathrm{s} 00421-015-3143-7$

Published: 04/03/2015

Peer reviewed version

Cyswllt i'r cyhoeddiad / Link to publication

Dyfyniad o'r fersiwn a gyhoeddwyd / Citation for published version (APA):

Riddle, T. G., Dolci, A., Fortes, M. B., Walker, F. S., Haq, A., Riddle, T., \& Walsh, N. P. (2015). Repeated muscle damage blunts the increase in heat strain during subsequent exercise heat stress. European Journal of Applied Physiology, 115(7), 1577-1588.

https://doi.org/10.1007/s00421-015-3143-7

\section{Hawliau Cyffredinol / General rights}

Copyright and moral rights for the publications made accessible in the public portal are retained by the authors and/or other copyright owners and it is a condition of accessing publications that users recognise and abide by the legal requirements associated with these rights.

- Users may download and print one copy of any publication from the public portal for the purpose of private study or research.

- You may not further distribute the material or use it for any profit-making activity or commercial gain

- You may freely distribute the URL identifying the publication in the public portal ?

Take down policy

The final publication is available at Springer via http://dx.doi.org/10.1007/s00421-015-3143-7

Take down policy

If you believe that this document breaches copyright please contact us providing details, and we will remove access to the work immediately and investigate your claim. 
Repeated muscle damage blunts the increase in heat strain during subsequent exercise-heat-stress

Dolci, A., Fortes, M.B., Walker, F.S., Haq, A., Riddle, T., and Walsh, N.P.

College of Health and Behavioural Sciences, Bangor University, Gwynedd, UK.

\section{Address for correspondence:}

Prof. Neil P. Walsh,

Extremes Research Group,

School of Sport, Health and Exercise Sciences,

College of Health and Behavioural Sciences,

Bangor University,

Bangor,

LL57 2PZ, UK.

Telephone: $\quad$ +44 1248383480

Fax: $\quad$ +44 1248371053

E-mail: n.walsh@bangor.ac.uk 


\section{ABSTRACT}

Purpose: Exercise-induced muscle-damage (EIMD) has recently been shown to increase heat strain during exercise-heat-stress (HS), and represents a risk factor for exertional heat illness (EHI). We hypothesised that a repeated-bout of EIMD blunts the increase in rectal temperature $\left(T_{\mathrm{re}}\right)$ during subsequent endurance exercise in the heat. Methods: Sixteen non-heat-acclimated males were randomly allocated to $\operatorname{EIMD~}(n=9)$ or control $(\mathrm{CON}, n=7)$. EIMD performed a downhill running treatment at $-10 \%$ gradient for 60 min at $65 \% \dot{\mathrm{V}}$ $\mathrm{O}_{2 \max }$ in $20^{\circ} \mathrm{C}, 40 \% \mathrm{RH}$. CON participants performed the same treatment but at $+1 \%$ gradient. Following treatment, participants rested for $30 \mathrm{~min}$, then performed HS (+1\% gradient running for $40 \mathrm{~min}$ at $65 \% \dot{\mathrm{V}}$ $\mathrm{O}_{2 \max }$ in $33^{\circ} \mathrm{C}, 50 \% \mathrm{RH}$ ) during which thermoregulatory measures were assessed. Both groups repeated the treatment and subsequent HS 14-days later. Isometric quadriceps strength was assessed at baseline, and 48-h post treatment. Results: The decrease in leg strength 48-h post EIMD trial 1 (-7.5\%), was absent 48-h post EIMD trial $2(+2.9 \%)$ demonstrating a repeated-bout-effect. Final $T_{\text {re }}$ during HS was lower following EIMD trial $2\left(39.25 \pm 0.47^{\circ} \mathrm{C}\right)$ compared with EIMD trial $1\left(39.59 \pm 0.49^{\circ} \mathrm{C}, P<0.01\right)$, with CON showing no difference. Thermal sensation and the $T_{\text {re }}$ threshold for sweating onset were also lower during HS on EIMD trial 2. Conclusion: The repeated-bout-effect blunted the increase in heat strain during HS conducted after EIMD. Incorporating a muscle-damaging bout into training could be a strategy to reduce the risk of EHI and improve endurance performance in individuals undertaking heavy exercise with an eccentric component in the heat.

KEYWORDS: Thermoregulation; eccentric; inflammation; muscle-injury; hyperthermia; cross-adaptation, heat-illness, heat stroke 


\section{INTRODUCTION}

Exercising in hot conditions poses one of the greatest challenges to homeostasis of the human body (Armstrong et al. 2007; Sawka et al. 2011). If heat production during exercise is not effectively dissipated, core body temperature can rise to dangerous levels, thereby placing the individual at risk of developing exertional heat-illness (EHI) (Armstrong et al. 2007), or the more serious, and potentially fatal condition of exertional heat stroke (EHS) (Casa et al. 2012; Sawka et al. 2011). In addition to exercising in hot and humid environments, a number of risk factors for EHI/EHS have been identified, including; inappropriate clothing, inadequate heat-acclimation, high body mass index, poor physical fitness, dehydration, and underlying medical conditions (Armstrong et al. 2007; Epstein et al. 1999; Rav-Acha et al. 2004; Sawka et al. 2011). Other potential risk factors, which are less well supported include disruption of sleep, and the circulating inflammatory response (Bouchama 1995; Lim and Mackinnon 2006; Moore et al. 2013; Shephard and Shek 1999).

Highly motivated, well trained athletes, who may ignore normal thermoregulatory behavioural cues, and military personnel, in whom evaporative cooling is limited due to their occupational clothing, and where exercise intensity is often externally regulated, are two groups who may be at particular risk of EHI/EHS (DeMartini et al. 2014). A number of deaths in athletes and military personnel each year are attributed to EHS (Carter, III et al. 2005; Casa et al. 2012; Rav-Acha et al. 2004). These groups regularly perform multiple bouts of heavy exercise, often within a short time span and in hot environmental conditions, and potentially involving an eccentric component (e.g. walking downhill/jumping/lunging etc.). We (Fortes et al. 2013), and others (Montain et al. 2000), have shown that prior exercise-induced muscle-damage (EIMD) increases heat strain during exercise-heat-stress conducted shortly after muscle damage. For example, final rectal temperature $\left(T_{\mathrm{re}}\right)$ was $0.53^{\circ} \mathrm{C}$ higher during $40 \mathrm{~min}$ of moderate exercise-heat-stress conducted $30 \mathrm{~min}$ after 1-hour of EIMD, compared to identical exercise-heat-stress conducted $30 \mathrm{~min}$ after 1-hour of nonmuscle-damaging control exercise (Fortes et al. 2013). This increased heat strain suggests that performing exercise with an eccentric component may represent an additional risk factor for EHI. 
Clearly, it is of interest to investigate, and adopt strategies that may reduce the risk of EHI. It is plausible that reducing the degree of muscle damage encountered will also lessen the degree of heat strain encountered. One obvious, but unexplored avenue of investigation is the well-known repeated bout effect of muscle-damaging exercise, where a single session of eccentric exercise induces adaptations resulting in less evidence of damage when the exercise bout is repeated (Clarkson et al. 1992; Clarkson and Hubal 2002; McHugh et al. 1999). The mechanism to explain this repeated bout effect is not fully understood, though likely involves neural, cellular and mechanical mechanisms (Clarkson et al. 1992; Clarkson and Hubal 2002; McHugh et al. 1999). In our previous study (Fortes et al. 2013), increased circulating interleukin (IL)-6 concentration following EIMD was associated with increased heat strain during subsequent exercise heat stress, a pertinent finding due to a potential inflammatory role in the aetiology of EHI/EHS (Bouchama 1995; Lim and Mackinnon 2006; Shephard and Shek 1999). A dampening of the inflammatory response is one proposed explanation for the repeated bout effect (Pizza et al. 1996), and given that there is some evidence that circulating IL- 6 concentration is reduced following a second, repeated bout of EIMD compared with the first bout (Smith et al. 2007) this may provide a mechanism for a potential beneficial repeated bout effect in reducing heat strain.

With this in mind, the aim of this study was to investigate the influence of the EIMD repeated-bout-effect upon heat strain during subsequent exercise in the heat. To this end, we had non-heat-acclimated participants perform muscle-damaging exercise using a downhill running model, and then assessed heat strain during an exercise-heat-stress test conducted $30 \mathrm{~min}$ post EIMD to coincide with the circulating inflammatory response. This procedure was then repeated 14 days later. We hypothesised that the second (repeated) bout of EIMD would blunt the increase in $T_{\text {re }}$ during subsequent exercise-heat-stress compared with the first EIMD trial. In order to discount any potential temporary heat acclimation, or passage of time effects, a separate control group undertook all identical procedures, except that non-muscle damaging exercise was performed instead of EIMD. 
ABBREVIATIONS:

$\mathrm{CON}$ - Control group

eHsp72 - Extracellular heat shock protein 72

EIMD - Exercise-induced muscle damage

HR - Heart rate

HS - Exercise-heat-stress test

Hsp - Heat shock protein

IL - Interleukin

$\dot{M}$ - Metabolic energy expenditure

NBM - Nude body mass

RER - Respiratory exchange ratio

RH - Relative humidity

RPE - Rating of perceived exertion

TNF - Tumour necrosis factor

$T_{\text {re }}-$ Rectal core temperature

$T_{\mathrm{sk}}-$ Skin temperature

$\mathrm{VO}_{2 \max }-$ Maximal oxygen uptake

WURSS - Wisconsin upper respiratory symptom survey 


\section{METHODS}

\section{Participants}

Sixteen healthy, physically-active males volunteered to participate in the study, giving fully-informed consent in writing. The study received local ethical approval and was conducted according to the standards required by the Declaration of Helsinki. Characteristics of the participants were as follows: (Mean \pm standard deviation): age, $21.9 \pm 1.7 \mathrm{yr}$; nude body mass, $72.3 \pm 7.5 \mathrm{~kg}$; height, $176 \pm 7 \mathrm{~cm}$; body mass index, $23.1 \pm 1.9 \mathrm{~kg} \cdot \mathrm{m}^{-2}$; body surface area, $1.88 \pm 0.12 \mathrm{~m}^{2}$, and maximal oxygen uptake $\left(\mathrm{VO}_{2 \max }\right) 59 \pm 5 \mathrm{~mL} \cdot \mathrm{kg}$ ${ }^{1} \cdot \mathrm{min}^{-1}$. Participants were excluded if they were heat-acclimated, or regularly undertook downhill running or eccentric exercise as part of their normal training. Participants were non-smokers, and free from any known immune, cardiovascular or metabolic disease. To further confirm participants were free from upperrespiratory tract infections, on each of the 14 days preceding both main trials, participants completed an illness-specific questionnaire (WURSS-44) (Barrett et al. 2002). No participants were taking any medication (e.g. non-steroidal anti-inflammatory drugs) or generic supplementation. Participants were asked to refrain from exercise 72 hours prior to, and from alcohol and caffeine 24 hours prior to all exercise bouts.

\section{Study design}

Participants were randomised to one of two protocols, EIMD or CON. Nine participants completed an exercise-heat-stress-test $30 \mathrm{~min}$ after a treatment of muscle damaging exercise (EIMD: running downhill on $10 \%$ gradient) (trial 1). This protocol was repeated two weeks later (trial 2). A separate control group (CON, $n=7$ ) performed energy expenditure equivalent non-muscle-damaging exercise treatment (CON: running at $+1 \%$ gradient), followed 30 min later by the exercise-heat-stress test, with the protocol repeated 14 days later. Thermoregulatory measurements ( $T_{\mathrm{re}}$, skin temperature $\left(T_{\mathrm{sk}}\right)$, sweating rate), perceptual measures (thermal sensation, rating of perceived exertion), heart rate, and metabolic energy expenditure, were assessed throughout all heat stress tests. Blood samples were collected at pre-treatment, pre, post and 1-hour post HS on all trials and assessed for circulating inflammatory markers IL-6, IL-10, and heat shock protein (Hsp) 72 concentration. Circulating extracellular (e)Hsp72 was measured as concentrations have been shown to 
increase following EIMD (Peake et al. 2005), eHsp72 itself may also have direct pyrogenic effects (Pastukhov et al. 2003), and it provides an additional measure of the inflammatory response due to its immune-stimulating capability (Asea et al. 2000; Whitham and Fortes 2008). Isometric leg strength of the quadriceps, and perceived muscle soreness were determined at baseline and 48-hours post trials to assess the degree of muscle damage. There were no differences in anthropometric or fitness data between the groups. An overview of the study design is presented in Fig 1.

*** Insert Fig. 1 here***

\section{Experimental procedures}

\section{Preliminary testing and familiarisation}

The $\mathrm{VO}_{2 \max }$ for each participant was determined by a continuous maximal incremental exercise test to exhaustion performed on a motorised treadmill (HP Cosmos Mercury 4.0, Nussdorf-Traunstein, Germany) (Fortes et al. 2013). Expired gas was analysed by an on-line breath-by-breath system (Cortex Metalyser 3B, Biophysik, Leipzig, Germany). After this, the treadmill running speed which elicited $65 \% \mathrm{VO}_{2 \max }$ running at $+1 \%$ gradient was obtained by interpolation of the running speed $-\mathrm{VO}_{2}$ relationship. A running speed verification was then conducted and employed as the running speed for the treatment on the CON group, and for the heat stress test for both groups. A subsequent verification was also performed on downhill running at $-10 \%$ gradient with expired gas analysed on a continuous basis, and with the running speed adjusted accordingly until $65 \% \mathrm{VO}_{2 \max }$ was attained. This downhill running verification took no more than 6 minutes, and the verified running speed was used during treatment on those assigned to muscle-damaging (EIMD) trials. Expired gas data were averaged every ten seconds over a period of two minutes during this process of verification. All instrumentation and procedures used in the experimental trials were also presented to participants at this time. Thirty minutes after this verification was completed, maximal isometric leg strength was measured to assess participants' baseline quadriceps leg-strength within 7 days of the first experimental trial. Diet diaries were provided to record all food consumed during the 24 hours prior 
to, and during the first experimental trial, and participants were instructed to replicate this before and during the second trial 14 days later.

\section{Experimental trials}

On the day of each experimental trial participants reported to the laboratory (ambient temperature $20{ }^{\circ} \mathrm{C}$ and relative humidity (RH) $40 \%$ ) at 07:10 am having fasted overnight. Participants were provided fluids to consume $\left(40 \mathrm{~mL} \cdot \mathrm{kg}^{-1} \cdot \mathrm{NBM} \cdot \mathrm{d}^{-1}\right)$ in the prior 24 -hour period to ensure they began exercise euhydrated. This was verified by checking that urine-specific gravity (Atago Uricon-Ne refractometer, Atago Co., Ltd. Tokyo, Japan.) upon arrival was less than 1.028 (Armstrong et al. 2010). Participants fasted condition was verified by a finger-prick blood sample analysed for glucose and ensuring the reading was $<6 \mathrm{mg} \cdot \mathrm{dl}^{-1}$ (ACCUCHECK Aviva, Roche, Basel, Switzerland). Participants' nude body mass (NBM) was then measured on a digital platform scale accurate to the nearest $50 \mathrm{~g}$ (model 705, Seca, Hamburg, Germany). A cereal bar equivalent to $8.4 \mathrm{~kJ} \cdot \mathrm{kg}^{-1} \mathrm{NBM}$ and water $\left(5 \mathrm{ml} \cdot \mathrm{kg}^{-1} \mathrm{NBM}\right)$ was subsequently provided to participants based on this body mass. At 08:15am, baseline NBM was measured, and a resting blood sample was taken before the participant fitted a rectal thermistor and heart rate monitor (Polar Electro, Kempele, Finland). The participants also rated their perceived muscle soreness at this stage.

\section{Exercise trial treatment}

The exercise trial treatment (EIMD or CON) started at 08:30 am, with standardised clothes worn by participants (e.g. running shorts, socks and shoes). Participants ran for $60 \mathrm{~min}$ at the individualised predetermined speed that reflected $65 \% \mathrm{VO}_{2 \max }$ on either $+1 \%$ gradient $(\mathrm{CON})$ or $-10 \%$ gradient (EIMD). Rectal core temperature and heart rate (HR) were assessed every $10 \mathrm{~min}$, and $60 \mathrm{~s}$ expired gas samples were collected by Douglas bag method at 20 and $40 \mathrm{~min}$ of exercise, and analysed for $\mathrm{VO}_{2}$. Water $\left(2 \mathrm{~mL} \cdot \mathrm{kg}^{-}\right.$ ${ }^{1} \mathrm{NBM}$ ) was provided throughout treatment every $15 \mathrm{~min}$. 


\section{Exercise heat stress}

After the treatment, participants sat for $30 \mathrm{~min}$ in a temperature controlled environment $\left(20^{\circ} \mathrm{C}\right)$ during which skin thermistors were applied (Grant EUS-U, Cambridge, UK). Participants were provided with a standardised amount of fluids $\left(2.5 \mathrm{~mL} \cdot \mathrm{kg}^{-1} \mathrm{NBM}\right)$ during this time. A blood sample was collected and preheat stress NBM was determined just before the participant entered an environmental chamber (Delta Environmental System, Chester, UK) which was kept at a dry bulb temperature of $33^{\circ} \mathrm{C}, 50 \% \mathrm{RH}$, and 0.2 $\mathrm{m} \cdot \mathrm{s}^{-1}$ face-on wind velocity. Immediately upon entering the chamber, a ventilated capsule was fastened to the forearm (for local sweating rate). Participants then began exercise-heat-stress (HS) by running without fluids, on a motorised treadmill at $+1 \%$ gradient for $40 \mathrm{~min}$ at the predetermined set running speed that reflected $65 \% \mathrm{VO}_{2 \max }$. Throughout $\mathrm{HS}$, the following measurements were taken: local forearm sweating rate, HR, $T_{\text {re }}$, physiological strain index (Moran et al. 1998) and skin temperature ( $\left.T_{\text {sk }}\right)$ continuously; rating of perceived exertion (RPE, Borg 6-20 scale (Borg 1982)) and thermal sensation (McGinnis 0-13 points (Hollies and Goldman 1977)) every $5 \mathrm{~min}$; and $60 \mathrm{~s}$ expired gas samples by Douglas bag method $\left(\mathrm{VO}_{2}\right)$ every $10 \mathrm{~min}$ of exercise. Immediately after HS, participants were removed from the chamber, seated, and a blood sample was taken after a standardised period of 3 min (post HS). Post HS NBM (following towelled drying) was also determined at this time. Water was provided to replace sweat losses encountered during HS. A further blood sample was taken 1-h post HS. Participants were then provided with a standardised meal $(3290 \mathrm{~kJ})$, and fluids to consume until they came back to the laboratory 48-h later for assessment of leg strength and perceived muscle soreness. Participants were required to refrain from any exercise, or ingesting caffeine or alcohol in this 48 -h intervening period. The participant left the laboratory and returned 14 days later to repeat the trial (trial 2).

\section{Measurements and instrumentation}

\section{Assessment of muscle damage}

Isometric right-leg quadriceps strength was assessed on a dynamometer (HUMAC norm, CSMi, Stoughton, MA, USA). Participants were sat upright and strapped in on their upper extremities to limit excess motion. 
The chair was adjusted so that the pivot was located on the lateral epicondyle of their right leg. A lever was applied to the right leg and adjusted so that the pad was located on the inferior part of the tibialis anterior. This lever was locked in at an angle of $70^{\circ}$ leg extension. A warm-up protocol consisted of six sub-maximal repetitions (two repetitions at $25 \%, 50 \%$ and $75 \%$ of perceived effort) with a $30 \mathrm{~s}$ recovery between each repetition. Following a 2 min rest period, participants were required to exert maximal isometric force against the lever pad. Verbal encouragement was given throughout each repetition. Isometric leg strength of the quadriceps was determined by the peak torque elicited from four maximal $5 \mathrm{~s}$ contractions (with a $90 \mathrm{~s}$ recovery between each). A separate pilot study conducted within our laboratory showed that there was no learning effect for this test, and that peak torque determined from this test has a day-to-day co-efficient variation of $5.5 \%$. Perceived leg muscle soreness was self-rated by participants on a seven-point validated Likert scale (Vickers 2001), whilst walking up and down the laboratory. The participant was blinded to the scores they had previously reported.

\section{Body temperatures}

Rectal core temperature was assessed using a standard flexible, sterile, disposable thermistor (Henleys Medical Supplies Ltd, Herts, UK) inserted $12 \mathrm{~cm}$ beyond the anal sphincter, with temperature recorded using a data logger (YSI model 4000A, YSI, Dayton, USA). In both repeated trials participants used the same thermistor. Insulated thermistors (Grant EUS-U, Cambridge, UK) were attached to the skin via surgical tape which conducted heat and allowed evaporation (Hypafix, BSN medical GmbH, Hamburg, Germany), and were used to measure $T_{\mathrm{sk}}$ at four sites on the left side of the body (on the chest at a point equi-distant to the acromion process and the nipple, the anterior mid-bicep, the anterior mid-thigh, and the lateral calf). The amount of tape used was standardised both between and within participants. Temperature data were registered using a portable data logger (Grant SQ2020, Cambridge, UK). Mean $T_{\text {sk }}$ was calculated using a four-site weighted equation (Ramanathan 1964). 


\section{Sweating responses}

Whole-body sweating rate was estimated from nude body mass losses during HS. Local forearm sweating rate was measured by dew-point hygrometry. Anhydrous compressed nitrogen was passed through a $5 \mathrm{~cm}^{2}$ capsule placed on the lower arm ventral surface (half-way between the antecubital fossa and carpus), and connected to a hygrometry system (DS2000, Alpha Moisture System, UK). Local forearm sweating rate was calculated using the difference in water content between effluent and influent air and the flow rate $\left(1 \mathrm{~L} \cdot \mathrm{min}^{-}\right.$ ${ }^{1}$ ), and normalised for the skin surface area under the capsule (expressed in $\mathrm{mg} \cdot \mathrm{cm}^{-2} \cdot \mathrm{min}^{-1}$ ). Sweating threshold and sensitivity were calculated by plotting the individual relationship between local forearm sweating rate and $T_{\text {re }}$ values. A simple linear regression equation for the first 6 min of exercise was calculated, with the threshold $T_{\text {re }}$ for active thermoregulatory sweating defined as the $T_{\text {re }}$ at which local forearm sweating rate $=0.06 \mathrm{mg} \cdot \mathrm{cm}^{-2} \cdot \mathrm{min}^{-1}$ (Buettner 1959). Sweating sensitivity during the exercise transient phase was calculated as the slope of this linear regression line.

\section{Rate of metabolic energy expenditure $(\dot{M})$}

Oxygen consumption $\left(\mathrm{VO}_{2}\right)$ was calculated from $60 \mathrm{~s}$ expired air samples collected into a Douglas bag and analysed for $\mathrm{O}_{2}$ and $\mathrm{CO}_{2}$ concentrations by a paramagnetic and infrared gas analyser (Servomex 5200 Multipurpose, Crowborough, UK), and volume (Harvard Apparatus, Edenbridge, UK). Respiratory exchange ratio (RER) was calculated, and $\dot{M}$ was determined using $\mathrm{VO}_{2}\left(\mathrm{~L} \cdot \mathrm{min}^{-1}\right)$ and RER in the following equation (Nishi 1981):

$\dot{M}(\mathrm{~W})=\mathrm{VO}_{2}(21166[0.23(\mathrm{RER})+0.77]) / 60$.

\section{Blood collection, handling and analysis}

Whole blood samples were collected by venepuncture from an antecubital fossa vein and gathered into two $\mathrm{K}_{2}$ EDTA and one lithium-heparin vacutainer tubes (BD, Oxford, UK). Haematocrit (capillary method in 
triplicate) using a micro-haematocrit reader (Hawksley \& Sons Ltd., Lancing, UK) and haemoglobin concentration using a photometer (Haemocue, Sheffield, UK) were both analysed immediately on heparinised whole blood in triplicate with plasma volume change calculated (Dill and Costill 1974). The remaining whole blood was spun in a refrigerated centrifuge at $1500 \mathrm{~g}$ for $10 \mathrm{~min}$, with the plasma aspirated, aliquoted into reaction tubes, and frozen at $-80^{\circ} \mathrm{C}$ for subsequent analysis. Circulating IL- 6 and IL-10 concentrations were assessed on EDTA derived plasma using commercially-available high-sensitivity ELISAs (Quantikine® HS IL-6, HS600B; Quantikine® HS IL-10, HS100C, R\&D Systems Europe, Abingdon, UK). Circulating eHsp72 concentration was also assessed by commercially available ELISA (Hsp72 EIA kit, ADI-EKS-700B, Enzo Life Sciences LTD, Farmingdale, USA). Intra-assay co-efficient of variation for circulating IL-6, IL-10 and eHsp72 concentration was $3.2 \%, 5 \%$, and $3 \%$ respectively. For all biochemical analyses, all participants' samples were always assayed on the same plate.

\section{Statistical analysis}

A sample size calculation was performed $\left(\mathrm{G}^{*}\right.$ Power, 3.1.5) using mean and standard deviation $T_{\mathrm{re}}$ data from our previous study (Fortes et al. 2013). For a two-tailed test with alpha level set at 0.05 , and power set at 0.8 , it was deemed appropriate to recruit a minimum of 7 participants in each group to detect a meaningful difference in final $T_{\text {re }}$ during subsequent exercise in the heat. Due to recruitment randomisation, 9 participants were recruited into the EIMD group, and 7 into CON. All data were checked for normality and sphericity. Data were analysed within condition (i.e. EIMD trial $1 v s$ trial 2), using two way repeated measures ANOVA or paired t-tests as appropriate. Bonferroni-adjusted paired t-test post-hoc procedures were used to determine within-subject differences. Pearson product moment correlation was also performed to assess the relationship between change in leg strength $48 \mathrm{~h}$ after EIMD with change in $T_{\text {re }}$ during HS. All data were analysed using SPSS version 20 software (IBM, NY, USA). Data are presented as means \pm SD. Statistical significance was accepted as $P<0.05$. 


\section{RESULTS}

\section{Treatment responses}

The experimental model was successful in demonstrating a repeated bout effect of muscle damage, since the decrease in isometric leg strength 48h following EIMD trial 1 (-7.5\% vs baseline), was absent $48 \mathrm{~h}$ post EIMD $2(+2.9 \%$ vs baseline $)(P<0.01$ versus trial 1 , Fig $2 \mathrm{a})$, and increases in perceived muscle soreness 48-h post EIMD in trial 1, were blunted in trial $2(P<0.05$, Fig $2 \mathrm{c})$. The control group did not demonstrate any differences in leg strength $(P=0.37$, Fig $2 \mathrm{~b})$ or muscle soreness $(P=0.60$, Fig $2 \mathrm{~d})$ between trial 1 and trial 2. There were no differences between trials 1 and 2 in either EIMD or CON for $\Delta T_{\text {re }}$ during treatment $\left(\right.$ EIMD trial $1,1.84 \pm 0.35$, trial $2=1.77 \pm 0.43{ }^{\circ} \mathrm{C}, P=0.53 ; \mathrm{CON}$ trial $1=1.36 \pm 0.49$, trial $2=1.48 \pm 0.43$ $\left.{ }^{\circ} \mathrm{C}, P=0.42\right)$.

*** Insert Fig. 2 here $* * *$

\section{Exercise heat stress responses}

\section{Rectal temperature, skin temperature and physiological strain index}

Rectal core and $T_{\text {sk }}$ responses to HS are presented in Fig 3. There were no significant differences in $T_{\mathrm{re}}$ and $T_{\text {sk }}$ responses to HS between CON trial 1 and CON trial 2 (Figs 3b,3d, 3f), confirming that there was no temporary heat acclimation effect of the first HS test on the second HS test or passage of time effect on heat strain responses to HS. All participants on EIMD had a lower final $T_{\text {re }}$ during HS on EIMD trial $2(39.25 \pm$ $\left.0.47^{\circ} \mathrm{C}\right)$ compared with EIMD trial $1\left(39.59 \pm 0.49{ }^{\circ} \mathrm{C}, P<0.01\right.$, Fig 3a), with only two participants showing evidence of mild hyperthermia during HS on EIMD trial 2 (final $T_{\mathrm{re}}>39.5^{\circ} \mathrm{C}$ ) compared with seven on EIMD trial 1. Physiological strain index was lower during HS on EIMD trial $2(6.8 \pm 2.8)$ compared with EIMD trial $1(7.3 \pm 3.1, P<0.01)$. There was no significant difference in starting $T_{\text {re }}$ between EIMD trials 1 and 2 before HS, but $T_{\text {re }}$ was significantly lower on EIMD trial 2 compared with EIMD trial 1 throughout HS (main effect of trial, $F=22.2, P<0.01)$, with a trend for an interaction $(F=2.9, P=0.09$, Fig $3 \mathrm{c})$. The $\Delta T_{\text {re }}$ during HS was also lower after EIMD trial $2\left(1.61 \pm 0.33{ }^{\circ} \mathrm{C}\right)$ than trial $1\left(1.81 \pm 0.40{ }^{\circ} \mathrm{C}, P<0.05\right)$ and the $\Delta T_{\mathrm{re}}$ 
during HS correlated moderately with leg strength loss 48 -h post EIMD $(r=0.46, P=0.05)$. There was no repeated bout effect on mean $T_{\mathrm{sk}}$ during HS following EIMD $(P=0.32)$, Fig $\left.3 \mathrm{e}\right)$.

*** Insert Fig. 3 here $* * *$

\section{Sweating rate and plasma volume change}

Whole body sweating rate was not different between the EIMD trials during HS (EIMD trial $1=23.3 \pm 5.0$, EIMD trial $\left.2=23.0 \pm 7.6 \mathrm{~mL} \cdot \mathrm{min}^{-1}, P=0.89\right)$, but there was a tendency for a higher local sweating rate on EIMD trial $2(F=2.6, P=0.08)$ during HS on EIMD trials (Fig 4a). Although there was no difference in sweating sensitivity between EIMD trials during the initial transient exercise phase $(P=0.17)$, the threshold temperature for sweating onset was significantly lower on EIMD trial 2 than EIMD trial 1 (EIMD trial $1=$ $37.74 \pm 0.16{ }^{\circ} \mathrm{C}$, EIMD trial $2=37.58 \pm 0.24{ }^{\circ} \mathrm{C}, P<0.05$; Fig $4 \mathrm{~b}$ ). No differences were observed during HS for sweating rate, sweating onset, or sweating sensitivity between CON trial 1 and 2. There was no effect on plasma volume change following HS on EIMD or CON trials.

$* * *$ Insert Fig. 4 here $* * *$

\section{Rate of metabolic energy expenditure, RER and HR}

There were no between-trial differences on EIMD for mean $\dot{M}$ (trial $1=1045 \pm 115$, trial $2=1030 \pm 128 \mathrm{~W}$, $P=0.21$ ), indicating no improvement in running economy between trials. These metabolic rates equated to $75 \% \pm 5 \%$ and $74 \% \pm 6 \% \mathrm{VO}_{2 \max }$ for EIMD trial 1 and trial 2 respectively, during HS. No difference was observed in mean RER or HR between EIMD trial 1 and EIMD trial 2 during HS (RER: EIMD trial $1=0.88$ \pm 0.03, EIMD trial $2=0.88 \pm 0.04, P=0.80, \mathrm{HR}$ EIMD trial $1=176 \pm 14$ beats $\cdot \mathrm{min}^{-1}$, EIMD trial $2=175 \pm$ 12 beats $\left.\cdot \min ^{-1}, P=0.54\right)$. 


\section{RPE and thermal sensation}

Thermal sensation and RPE data for EIMD are presented in Fig 5. Participants rated their thermal sensation lower throughout HS following EIMD trial 2 compared with trial 1 (main effect of trial, $F=6.5, P<0.05$, Fig 5a). There was a trend (main effect of trial, $F=3.7, P=0.09$ ) for participants to rate their perceived exertion lower during HS following EIMD trial 2 compared with EIMD 1 (Fig 5b). No differences were observed during HS for RPE or thermal sensation between CON trial 1 and 2.

$* * *$ Insert Fig. 5 here $* * *$

\section{Plasma IL-6 and IL-10, and eHsp72}

Circulating concentrations of IL-6, IL-10 and eHsp72 responses to EIMD are depicted in Fig 6. There was no EIMD repeated bout effect on the inflammatory response between trial 1 and 2 for IL-6 $(F=2.3, P=$ $0.11)$, IL-10 $(F=0.7, P=0.45)$, or eHsp72 concentrations $(F=0.8, P=0.45)$. Similarly, there were no between trial effects on CON for IL-6 $(F=0.9, P=0.44)$, IL-10 $(F=0.2, P=0.73)$, or eHsp72 concentration $(F=2.2, P=0.15)$

*** Insert Fig. 6 here *** 


\section{DISCUSSION}

We have recently shown that an acute bout of EIMD increases heat strain during subsequent exercise heat stress (HS), and thus, EIMD likely poses a risk factor for EHI (Fortes et al. 2013). The aim of the present study was to investigate if the well-known repeated bout effect for EIMD (Clarkson et al. 1992; McHugh et al. 1999) would blunt the increase in heat strain during subsequent exercise-heat-stress. In line with our hypothesis, heat strain was reduced $\left(0.34{ }^{\circ} \mathrm{C}\right.$ lower final $\left.T_{\text {re }}\right)$ during HS following the second EIMD bout, compared with the first bout. Furthermore, 7 of 9 participants showed evidence of mild hyperthermia (final $T_{\text {re }}>39.5^{\circ} \mathrm{C}$ ) during HS on EIMD trial 1 compared with only 2 of 9 participants during HS following EIMD trial 2. In addition, we observed a lower temperature threshold for sweating onset, a lower thermal sensation and a lower physiological strain index during HS after the second EIMD bout. This lessened heat strain during HS on the repeated EIMD trial was not due to temporary heat acclimation as a consequence of the first HS bout, nor due to passage of time effects, since no difference in heat strain was observed in the control group. By blunting the increase in thermal strain during exercise-heat-stress, incorporating a muscledamaging bout into training could be used as a practical strategy to reduce the risk of EHI, and improve exercise performance, in individuals undertaking subsequent heavy exercise bouts with an eccentric component in the heat.

Unaccustomed and/or heavy eccentric exercise is known to result in EIMD, and is characterised by decreased muscle strength, and increased muscle soreness in the days following EIMD (Clarkson et al. 1992; Clarkson and Hubal 2002). We utilised a downhill running model to evoke moderate, realistic muscle damage, evidenced by significant decreases in leg strength (-7.5\%), and increases in muscle soreness 48 -h post EIMD trial 1. This degree of muscle damage is equivalent to experiencing 'a light pain when walking'(Vickers 2001) and therefore likely reflects the degree of muscle damage that may be encountered by soldiers and athletes undergoing unaccustomed exercise with an eccentric component. Research has consistently shown, that a prior muscle damaging bout produces a protective adaptation that results in lesser symptoms of EIMD when the muscle damaging bout is repeated (e.g. blunted losses of leg strength, and reductions in muscle soreness) (Byrnes et al. 1985; Clarkson et al. 1992; McHugh et al. 1999). The success 
of the repeated bout effect was demonstrated herein, since leg strength was restored to baseline levels, and muscle soreness was significantly reduced 48-h following the repeated bout of EIMD.

Heat strain during HS was reduced following the second, repeated bout of EIMD compared with the first, with the $\Delta T_{\text {re }}$, and final $T_{\text {re }}$ reduced $0.2{ }^{\circ} \mathrm{C}$ and $0.34{ }^{\circ} \mathrm{C}$ respectively during $\mathrm{HS}$ on EIMD trial 2 compared with trial 1. The final $T_{\text {re }}$ on EIMD trial 2 was similar to the final $T_{\text {re }}$ observed in the control group during HS on both CON trials (Fig 3b), although we acknowledge that these groups were composed of different individuals, so are not directly comparable. In our previous study (Fortes et al. 2013), final $T_{\text {re }}$ was $0.53{ }^{\circ} \mathrm{C}$ higher during HS following EIMD compared to control non-muscle damaging exercise in a repeated measures design, whilst Montain et al (2000), also demonstrated $\sim 0.3{ }^{\circ} \mathrm{C}$ greater body temperature during HS following muscle damaging exercise compared to control exercise. It therefore appears that a prior bout of EIMD provides a significant degree of protection against the increased heat strain that EIMD elicits during subsequent exercise-heat-stress. We acknowledge the limitation that we did not establish a performance benefit due to the reduced heat strain but anticipate a delay in reaching a critical core temperature (purported to be $\sim 40{ }^{\circ} \mathrm{C}$ (Gonzalez-Alonso et al. 1999)) after repeated EIMD. Further research should investigate whether the observed reduction in thermal strain with repeated EIMD translates into a meaningful performance improvement. In this regard, its noteworthy that a similar reduction in final exercising $T_{\text {re }}\left(-0.3{ }^{\circ} \mathrm{C}\right)$ during exercise-heat-stress after $5 \mathrm{~d}$ heat acclimation brought about a $14 \%$ improvement in endurance performance during exercise in the heat (Garrett et al. 2009). We can have added confidence in our findings, since a particular strength of the current study is that a comparable control group was used in order to discount confounding heat acclimation or passage of time effects. Previous research has also shown no effect of a single prior heat stress bout on subsequent thermoregulatory responses during exercise heat stress conducted 14 days later (Barnett and Maughan 1993).

The circulating IL-6 response to muscle damaging exercise has been shown to be higher compared with nonmuscle damaging exercise (Bruunsgaard et al. 1997), a finding supported by our previous study (Fortes et al. 2013) and where the elevated circulating IL-6 concentration following EIMD correlated with the final $T_{\mathrm{re}}$ attained during subsequent HS. An elevated circulating IL-6 prior to heat stress is significant, given a 
potential involvement of the acute inflammatory response in the aetiology of EHI (Bouchama 1995; Lim and Mackinnon 2006; Shephard and Shek 1999; Walsh et al. 2011). A "dampening" of the inflammatory response is one proposed explanation for the repeated bout effect (Pizza et al. 1996). Indeed, a previous study has shown reduced pro-inflammatory cytokines (IL-6), and increased anti-inflammatory cytokines (IL10) in the 12 hours following a repeated bout of muscle damage evoked by downhill running (Smith et al. 2007), although this finding is not supported by studies that have used different models of muscle damage (e.g. isokinetic knee extensor exercise (Croisier et al. 1999; Willoughby et al. 2003)). We were therefore interested in whether the hypothesised reduction in heat strain could be accounted for by an altered circulating inflammatory response following EIMD. However, we did not observe any difference in proinflammatory IL-6 or anti-inflammatory IL-10 response either prior to, or after heat stress between the two EIMD bouts. It should be noted that in the study by Smith et al., cytokine concentrations were averaged over the 12 hour period following EIMD, thereby not providing useful information on the kinetics of the early inflammatory response immediately following EIMD (Smith et al. 2007). We also assessed eHsp72 concentration, which has been shown to be elevated following downhill running (Peake et al. 2005), and is also known to act as a "danger signal" activating the immune system (Horowitz and Robinson 2007; Whitham and Fortes 2008) including IL-6 (Asea et al. 2000). Furthermore, eHsp72 itself may have direct pyrogenic effects (Pastukhov et al. 2003). Nevertheless, we did not observe a difference in circulating eHsp72 concentration between EIMD trials. It is noteworthy however, that the circulating IL-6 and eHsp72 responses prior to HS during EIMD trial 1 were modest when compared with more metabolically challenging activities such as marathon running (Fehrenbach et al. 2005; Nieman et al. 2001), and therefore provided little margin for dampened responses.

Muscle damaging exercise increases steady state exercising $\mathrm{VO}_{2}$ following downhill running (Braun and Dutto 2003) and rodent models have shown decreased contraction economy in damaged muscle fibres (Warren, III et al. 1996). One might therefore anticipate improved running economy during HS on the second EIMD trial. However, this was not the case, since $\dot{M}$ during HS was similar on both EIMD trials. EIMD has also been shown to inhibit glycogen resynthesis (O'Reilly et al. 1987), yet altered metabolism is also an unlikely mechanism since RER was not different between EIMD trials. Whilst there was no effect on 
$T_{\mathrm{sk}}$, we did observe a lower temperature threshold for sweating onset, and a lower thermal sensation during HS on the second EIMD bout. The mechanism(s) for how a muscle-damaging bout of exercise $14 \mathrm{~d}$ earlier decreased the threshold $T_{\text {re }}$ for sweating onset during HS following a repeated-bout of EIMD remains unclear. There may be shared pathways with the concept of cross-tolerance, where adaptations to one stressor confer protection via molecular, cellular and neural interactions to other forms of stressor (Horowitz 2014; Horowitz and Robinson 2007). This process is thought to be mediated, in part, by intra-cellular heat shock proteins (Hsp's), and it has been suggested that acquired thermotolerance (the accumulation of protective Hsp's within cells following heat exposure), and systemic adaptations to heat acclimation share a common pathway (Kuennen et al. 2011). This may be pertinent since EIMD has been shown to increase Hsp72 and Hsp27 expression within muscle cells following EIMD (Paulsen et al. 2009; Thompson et al. 2001), and that the changes we observed during HS on EIMD trial 2, reflect similar adaptations to that observed during heat acclimation (reduced exercising $T_{\mathrm{re}}$, earlier sweating onset, reduced thermal sensation). Furthermore, a smaller intracellular heat shock response is shown in heat-intolerant military personnel (Moran et al. 2006). We acknowledge a limitation of the current study is that we did not assess intra-cellular Hsp's. It is possible that increases in Hsp's within muscle cells following the first EIMD bout confer some degree of heat acclimation evident $14 \mathrm{~d}$ later but future work is required to investigate this. It remains to be shown whether muscle-damaging exercise provides cross-tolerance against other novel stressors.

Non-heat-acclimated individuals undertaking heavy training bouts with an eccentric component in the heat are likely at increased risk of developing EHI (Fortes et al. 2013; Montain et al. 2000) e.g. athletes performing unaccustomed exercise, or soldiers running or walking across mountainous terrain. Considered alongside our present findings this work might help to explain, at least in part, why EHS in athletes, soldiers and labourers typically occurs in the first four days of unaccustomed heavy exertion in the heat (Armstrong et al. 2007; Cluver 1932). The present findings indicate that this risk can be mitigated by incorporating a bout of muscle-damaging exercise into the training regimen, prior to travel/deployment to hot environments but this requires further investigation. Further research should also investigate the duration of the demonstrated protective effect and confirm whether other models of eliciting EIMD, e.g. drop-jumps, have a 
comparable protective effect to that shown here with downhill treadmill running, with the added practical benefit of allowing a large number of individuals to be treated at once.

\section{CONCLUSIONS}

The repeated-bout-effect blunted the increase in heat strain during exercise-heat-stress conducted after EIMD, as shown by reduced exercising $T_{\text {re }}$, reduced thermal sensation, and earlier sweating onset. Incorporating a muscle-damaging bout into training could be a strategy to reduce the risk of EHI and improve endurance performance in individuals undertaking heavy exercise with an eccentric component in the heat.

\section{ACKNOWLEDGEMENTS}

We would like to thank the following people for their valuable assistance with data collection: Robert Blake, Emily Hogarth, Debra Larmett and Mike Urquhart. We are also indebted to the participants for their time and co-operation. This study received no external funding. 
References

Armstrong LE, Casa DJ, Millard-Stafford M, Moran DS, Pyne SW, Roberts WO (2007) American College of Sports Medicine position stand. Exertional heat illness during training and competition. Med Sci Sports Exerc 39: 556-572

Armstrong LE, Pumerantz AC, Fiala KA, Roti MW, Kavouras SA, Casa DJ, Maresh CM (2010) Human hydration indices: acute and longitudinal reference values. Int J Sport Nutr Exerc Metab 20: 145-153

Asea A, Kraeft SK, Kurt-Jones EA, Stevenson MA, Chen LB, Finberg RW, Koo GC, Calderwood SK (2000) HSP70 stimulates cytokine production through a CD14-dependant pathway, demonstrating its dual role as a chaperone and cytokine. Nat Med 6: 435-442

Barnett A, Maughan RJ (1993) Response of unacclimatized males to repeated weekly bouts of exercise in the heat. Br J Sports Med 27: 39-44

Barrett B, Locken K, Maberry R, Schwamman J, Brown R, Bobula J, Stauffacher EA (2002) The Wisconsin Upper Respiratory Symptom Survey (WURSS): a new research instrument for assessing the common cold. J Fam Pract 51: 265

Borg GA (1982) Psychophysical bases of perceived exertion. Med Sci Sports Exerc 14: 377-381

Bouchama A (1995) Heatstroke: a new look at an ancient disease. Intensive Care Med 21: 623-625

Braun WA, Dutto DJ (2003) The effects of a single bout of downhill running and ensuing delayed onset of muscle soreness on running economy performed $48 \mathrm{~h}$ later. Eur J Appl Physiol 90: 29-34

Bruunsgaard H, Galbo H, Halkjaer-Kristensen J, Johansen TL, MacLean DA, Pedersen BK (1997) Exerciseinduced increase in serum interleukin-6 in humans is related to muscle damage. J Physiol 499: 833-841

Buettner KJ (1959) Diffusion of water vapor through small areas of human skin in normal environment. J Appl Physiol 14: 259-275

Byrnes WC, Clarkson PM, White JS, Hsieh SS, Frykman PN, Maughan RJ (1985) Delayed onset muscle soreness following repeated bouts of downhill running. J Appl Physiol 59: 710-715

Carter R, III, Cheuvront SN, Williams JO, Kolka MA, Stephenson LA, Sawka MN, Amoroso PJ (2005)

Epidemiology of hospitalizations and deaths from heat illness in soldiers. Med Sci Sports Exerc 37: 13381344

Casa DJ, Armstrong LE, Kenny GP, O'Connor FG, Huggins RA (2012) Exertional heat stroke: new concepts regarding cause and care. Curr Sports Med Rep 11: 115-123

Clarkson PM, Hubal MJ (2002) Exercise-induced muscle damage in humans. Am J Phys Med Rehabil 81: S52S69

Clarkson PM, Nosaka K, Braun B (1992) Muscle function after exercise-induced muscle damage and rapid adaptation. Med Sci Sports Exerc 24: 512-520

Cluver EH (1932) An analysis of ninety-two fatal heat-stroke cases on the Witwatersrand gold mines. S Afr Med J 6: 19-22 
Croisier JL, Camus G, Venneman I, Deby-Dupont G, Juchmes-Ferir A, Lamy M, Crielaard JM, Deby C, Duchateau J (1999) Effects of training on exercise-induced muscle damage and interleukin 6 production. Muscle Nerve 22: 208-212

DeMartini JK, Casa DJ, Belval LN, Crago A, Davis RJ, Jardine JJ, Stearns RL (2014) Environmental conditions and the occurrence of exertional heat illnesses and exertional heat stroke at the Falmouth Road Race. J Athl Train 49: 478-485

Dill DB, Costill DL (1974) Calculation of percentage changes in volumes of blood, plasma, and red cells in dehydration. J Appl Physiol 37: 247-248

Epstein Y, Moran DS, Shapiro Y, Sohar E, Shemer J (1999) Exertional heat stroke: a case series. Med Sci Sports Exerc 31: 224-228

Fehrenbach E, Niess AM, Voelker K, Northoff H, Mooren FC (2005) Exercise intensity and duration affect blood soluble HSP72. Int J Sports Med 26: 552-557

Fortes MB, Di FU, Dolci A, Junglee NA, Crockford MJ, West L, Hillier-Smith R, Macdonald JH, Walsh NP (2013) Muscle-damaging exercise increases heat strain during subsequent exercise heat stress. Med Sci Sports Exerc 45: 1915-1924

Garrett AT, Goosens NG, Rehrer NJ, Patterson MJ, Cotter JD (2009) Induction and decay of short-term heat acclimation. Eur J Appl Physiol 107: 659-670

Gonzalez-Alonso J, Teller C, Andersen SL, Jensen FB, Hyldig T, Nielsen B (1999) Influence of body temperature on the development of fatigue during prolonged exercise in the heat. J Appl Physiol 86: 10321039

Hollies NRS, Goldman RFG (1977) Psychological scaling in comfort assessment. In: Hollies NRS, Goldman RFG (eds) Clothing Comfort: Interaction of Thermal, Ventilation, Construction, and Assessment Factors. Ann Arbor Science Publishers, Ann Arbor, pp 107-120

Horowitz M (2014) Heat acclimation, epigenetics, and cytoprotection memory. Compr Physiol 4: 199-230

Horowitz M, Robinson SD (2007) Heat shock proteins and the heat shock response during hyperthermia and its modulation by altered physiological conditions. Prog Brain Res 162: 433-446

Kuennen M, Gillum T, Dokladny K, Bedrick E, Schneider S, Moseley P (2011) Thermotolerance and heat acclimation may share a common mechanism in humans. Am J Physiol Regul Integr Comp Physiol 301: R524-R533

Lim CL, Mackinnon LT (2006) The roles of exercise-induced immune system disturbances in the pathology of heat stroke : the dual pathway model of heat stroke. Sports Med 36: 39-64

McHugh MP, Connolly DA, Eston RG, Gleim GW (1999) Exercise-induced muscle damage and potential mechanisms for the repeated bout effect. Sports Med 27: 157-170

Montain SJ, Latzka WA, Sawka MN (2000) Impact of muscle injury and accompanying inflammatory response on thermoregulation during exercise in the heat. J Appl Physiol 89: 1123-1130

Moore JP, Harper Smith AD, Di FU, Walsh NP (2013) Three nights of sleep deprivation does not alter thermal strain during exercise in the heat. Eur J Appl Physiol 113: 2353-2360 
Moran DS, Eli-Berchoer L, Heled Y, Mendel L, Schocina M, Horowitz M (2006) Heat intolerance: does gene transcription contribute? J Appl Physiol 100: 1370-1376

Moran DS, Shitzer A, Pandolf KB (1998) A physiological strain index to evaluate heat stress. Am J Physiol 275: R129-R134

Nieman DC, Henson DA, Smith LL, Utter AC, Vinci DM, Davis JM, Kaminsky DE, Shute M (2001) Cytokine changes after a marathon race. J Appl Physiol 91: 109-114

Nishi Y (1981) Measurement of thermal balance in man. In: Cena K, Clark JA (eds) Bioengineering, Thermal Physiology and Comfort. Elsevier, New York, pp 29-39

O'Reilly KP, Warhol MJ, Fielding RA, Frontera WR, Meredith CN, Evans WJ (1987) Eccentric exercise-induced muscle damage impairs muscle glycogen repletion. J Appl Physiol 63: 252-256

Pastukhov I, Ekimova IV, Guzhova IV (2003) Major stress protein has pyrogenic action. Dokl Biol Sci 388: 4144

Paulsen G, Lauritzen F, Bayer ML, Kalhovde JM, Ugelstad I, Owe SG, Hallen J, Bergersen LH, Raastad T (2009) Subcellular movement and expression of HSP27, alphaB-crystallin, and HSP70 after two bouts of eccentric exercise in humans. J Appl Physiol 107: 570-582

Peake JM, Suzuki K, Hordern M, Wilson G, Nosaka K, Coombes JS (2005) Plasma cytokine changes in relation to exercise intensity and muscle damage. Eur J Appl Physiol 95: 514-521

Pizza FX, Davis BH, Henrickson SD, Mitchell JB, Pace JF, Bigelow N, DiLauro P, Naglieri T (1996) Adaptation to eccentric exercise: effect on CD64 and CD11b/CD18 expression. J Appl Physiol 80: 47-55

Ramanathan NL (1964) A new weighting system for mean surface temperature of the human body. J Appl Physiol 19: 531-533

Rav-Acha M, Hadad E, Epstein Y, Heled Y, Moran DS (2004) Fatal exertional heat stroke: a case series. Am J Med Sci 328: 84-87

Sawka MN, Leon LR, Montain SJ, Sonna LA (2011) Integrated physiological mechanisms of exercise performance, adaptation, and maladaptation to heat stress. Compr Physiol 1: 1883-1928

Shephard RJ, Shek PN (1999) Immune dysfunction as a factor in heat illness. Crit Rev Immunol 19: 285-302

Smith LL, McKune AJ, Semple SJ, Sibanda E, Steel H, Anderson R (2007) Changes in serum cytokines after repeated bouts of downhill running. Appl Physiol Nutr Metab 32: 233-240

Thompson HS, Scordilis SP, Clarkson PM, Lohrer WA (2001) A single bout of eccentric exercise increases HSP27 and HSC/HSP70 in human skeletal muscle. Acta Physiol Scand 171: 187-193

Vickers AJ (2001) Time course of muscle soreness following different types of exercise. BMC Musculoskelet Disord 2: 5

Walsh NP, Gleeson M, Pyne DB, Nieman DC, Dhabhar FS, Shephard RJ, Oliver SJ, Bermon S, Kajeniene A (2011) Position statement. Part two: Maintaining immune health. Exerc Immunol Rev 17: 64-103

Warren GL, III, Williams JH, Ward CW, Matoba H, Ingalls CP, Hermann KM, Armstrong RB (1996) Decreased contraction economy in mouse EDL muscle injured by eccentric contractions. J Appl Physiol 81: 2555-2564 
Whitham M, Fortes MB (2008) Heat shock protein 72: release and biological significance during exercise. Front Biosci 13: 1328-1339

Willoughby DS, McFarlin B, Bois C (2003) Interleukin-6 expression after repeated bouts of eccentric exercise. Int J Sports Med 24: 15-21

\section{FIGURE LEGENDS}

Fig 1 Schematic of experimental procedures. EIMD, exercise induced muscle damage; CON, energy expenditure equivalent control exercise; HS, exercise heat stress; $\mathrm{RH}$, relative humidity. $\dagger$ denotes blood sampling time points

Fig 2 Markers of muscle damage (leg strength peak torque and muscle soreness) assessed 48-h after either 60 min exercise-induced muscle damage (-10\% gradient running at $65 \% \mathrm{VO}_{2 \max }$, EIMD, triangles, $\left.n=9\right)$ or 60 min of control exercise $\left(+1 \%\right.$ gradient running at $65 \% \mathrm{VO}_{2 \max }, \mathrm{CON}$, circles, $\left.n=7\right)$. Trial 1 represents the first bout, trial 2 represents the repeated bout performed 14d later. Individual responses are shown, with mean data shown as solid black squares. \# $P<0.05$, \#\#P $<0.01$ vs trial 1

Fig 3 Final rectal temperature ( $T_{\mathrm{re}}$, a and b), absolute rectal temperature ( $T_{\mathrm{re}}, \mathrm{c}$ and d) and mean skin temperature $\left(T_{\mathrm{sk}}\right.$, e and $\mathrm{f}$ ) responses during exercise-heat-stress tests which involved running for $40 \mathrm{~min}$ at $65 \% \mathrm{VO}_{2 \max }$ in $33^{\circ} \mathrm{C}, 50 \% \mathrm{RH}$ conducted $30 \mathrm{~min}$ after treatment which involved either exercise-induced muscle damage (-10\% gradient running, EIMD, triangles, $n=9)$ or control exercise $(+1 \%$ gradient running, CON, circles, $n=7$ ). Note: due to individual skin thermistors becoming detached during HS, $T_{\text {sk }}$ data (figs e and $\mathrm{f}$ ) are presented in those with a full data set ( $n=7 \mathrm{EIMD}, n=6 \mathrm{CON})$. Individual responses are shown for final $T_{\mathrm{re}}$ (a and b), with mean data shown as solid black squares (\#\# $P<0.01$ versus trial 1 ). For panels cf, mean \pm SD data are shown, with trial 1 representing the first bout (filled symbols), and trial 2 representing the repeated bout performed 14d later (open symbols). § Trial 2 significantly lower than trial 1 (main effect of trial, $P<0.05)$ 
Fig 4 Local forearm sweating rate reported as a function of time (a), and as a function of rectal temperature $\left(T_{\text {re }}\right.$, b) during exercise-heat-stress tests which involved running for 40 min at $65 \% \mathrm{VO}_{2 \max }$ in $33^{\circ} \mathrm{C}, 50 \% \mathrm{RH}$ conducted 30 min after exercise-induced muscle damage (-10\% gradient running, $n=9)$. Trial 1 represents the first bout (filled triangles), trial 2 represents the repeated bout performed 14d later (open triangles). Values are means $\left( \pm \mathrm{SD}\right.$ in fig a). \# Significantly different $T_{\mathrm{re}}$ for sweating onset $(P<0.05)$

Fig 5 Thermal sensation (a), and rating of perceived exertion (RPE, b) during exercise-heat-stress tests which involved running for $40 \mathrm{~min}$ at $65 \% \mathrm{VO}_{2 \max }$ in $33^{\circ} \mathrm{C}, 50 \% \mathrm{RH}$ conducted $30 \mathrm{~min}$ after exercise-induced muscle damage (-10\% gradient running, $n=9)$. Trial 1 represents the first bout (filled triangles), trial 2 represents the repeated bout performed 14d later (open triangles). § Trial 2 significantly lower than trial 1 (main effect of trial, $P<0.05$ ). Data are mean $\pm \mathrm{SD}$

Fig 6 Plasma interleukin (IL)-6 (a), plasma IL-10 (b), and extracellular heat shock protein (Hsp) 72 (c) concentrations at baseline, pre, post and 1h-post exercise-heat stress (HS), which involved running for 40 $\min$ at $65 \% \mathrm{VO}_{2 \max }$ in $33^{\circ} \mathrm{C}, 50 \% \mathrm{RH}$, conducted $30 \mathrm{~min}$ after exercise-induced muscle damage $(-10 \%$ gradient running, $n=9$ ). Trial 1 represents the first bout (filled triangles), trial 2 represents the repeated bout performed 14d later (open triangles). No significant effects. Data are mean \pm SD 
Fig 1

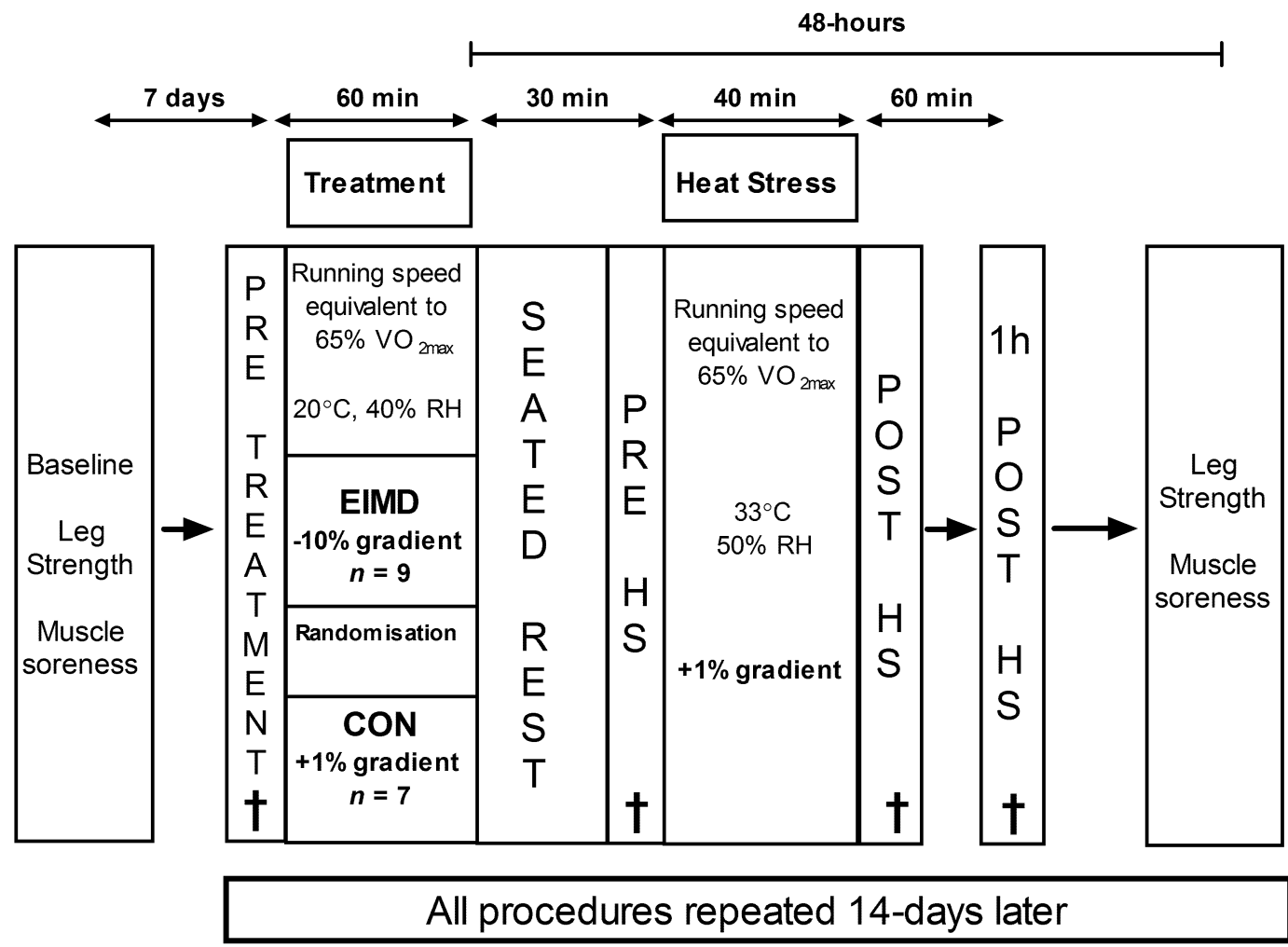

Fig 2
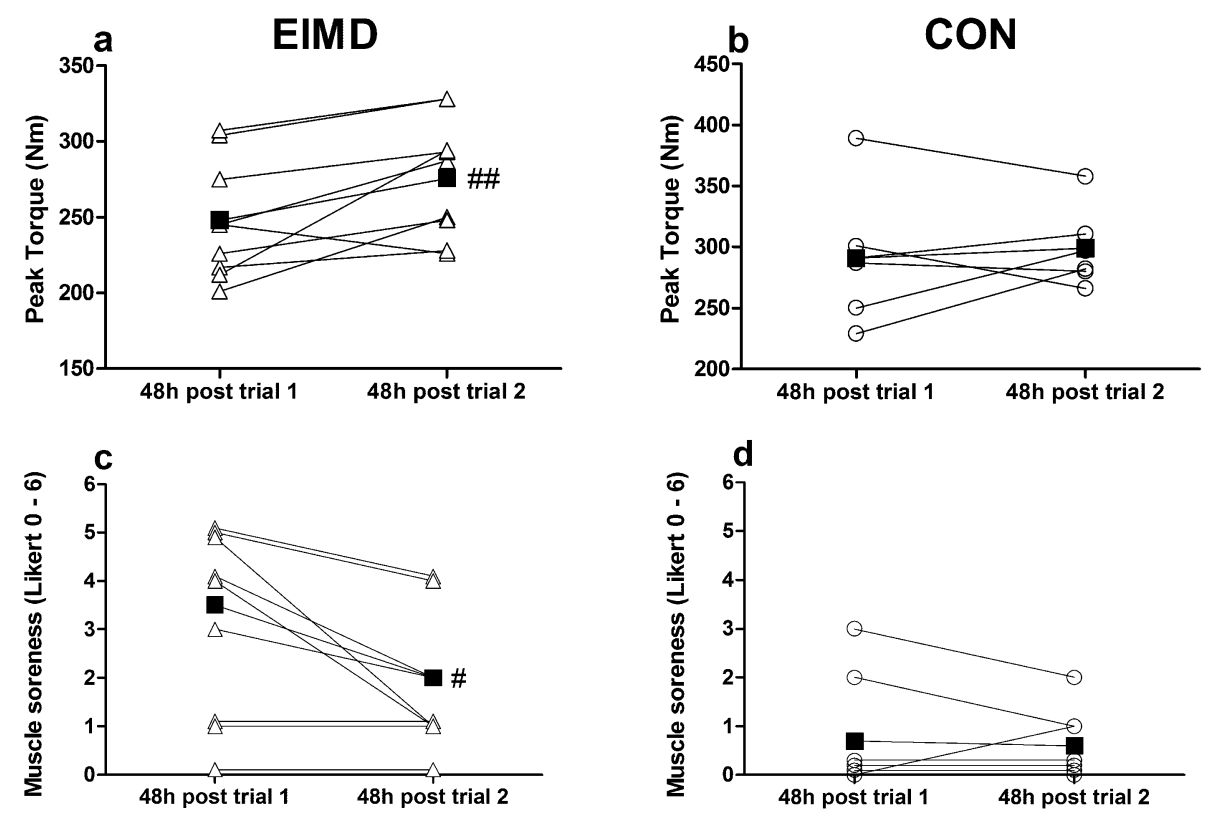
Fig 3
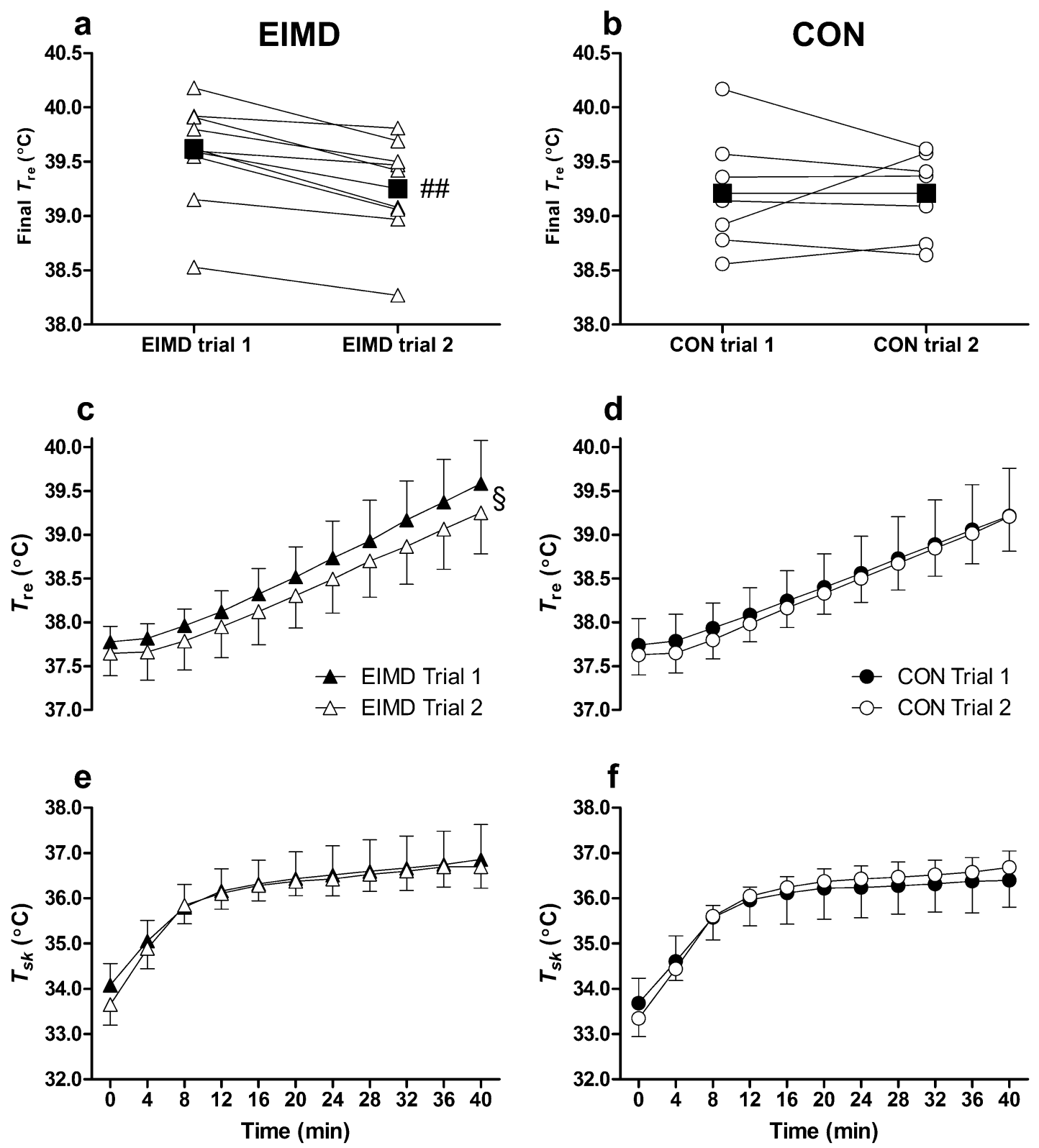
Fig 4
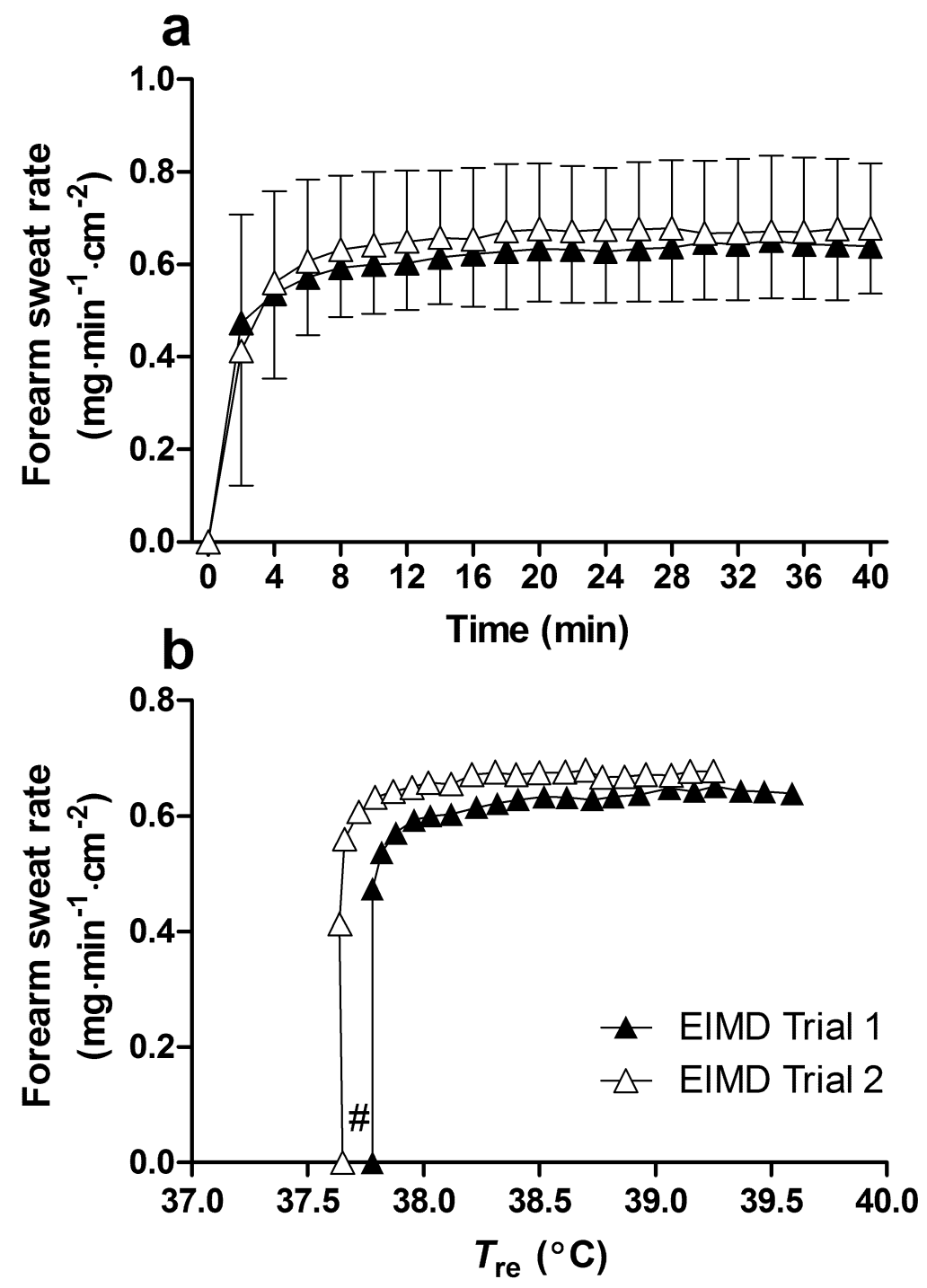
Fig 5
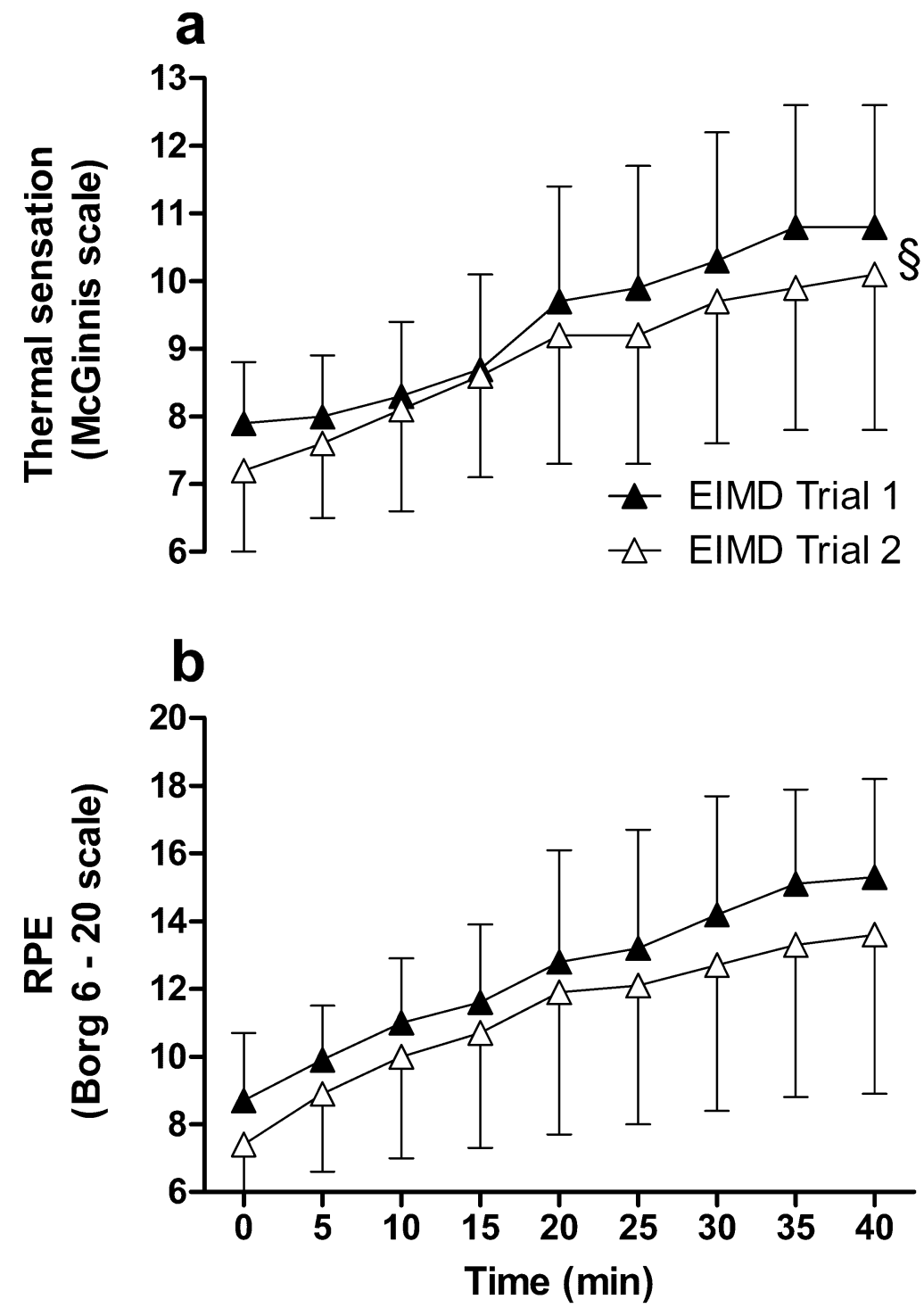
Fig 6
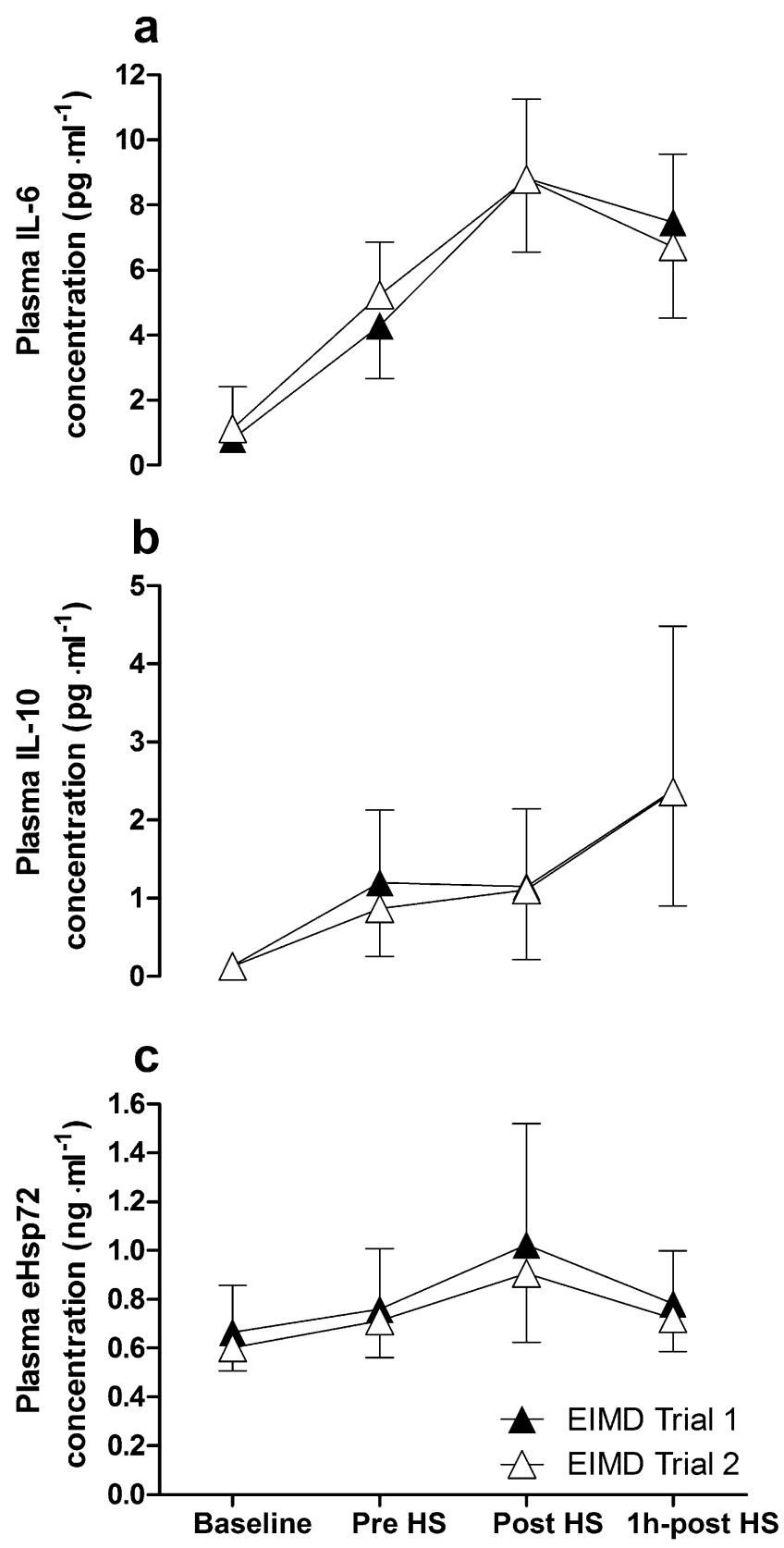